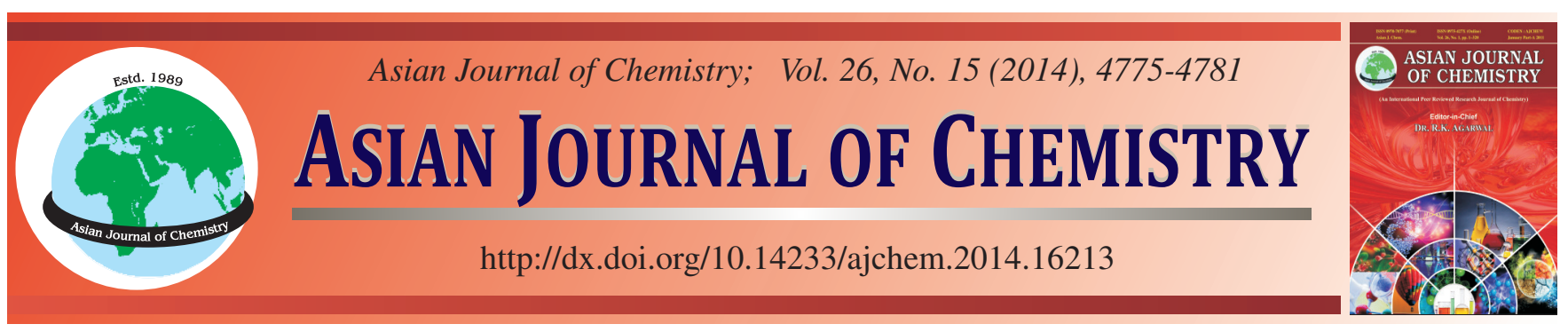

\title{
Preparation of Regenerated Cellulose Fiber from Bamboo Fiber
}

\author{
Shuangquan $\mathrm{YaO}^{1}$, ShuangXi Nie ${ }^{1}$, Fenjie Niu ${ }^{1}$, Guoxin $\mathrm{XUE}^{2}$ and Shuangfei $\mathrm{WANG}^{1}{ }^{1, *}$
}

${ }^{1}$ College of Light Industry and Food Engineering, Guangxi University, Nanning 530004, P.R. China

${ }^{2}$ College of Materials and Textiles, Zhejiang Sci-Tech University, Hangzhou 310018, P.R. China

*Corresponding author: Fax: +86 771 3237097; Tel: +86 13877183856; E-mail: wangsf@gxu.edu.cn

This work discusses preparation technology research based on bamboo raw material of regenerated cellulose fiber pulp. First make two sets of single factor analysis of hot water extraction hemicellulose: single factor analysis of prehydrolysis temperature, single factor analysis of prehydrolysis time. Then formulate the conditions of cooking, the highest cooking temperature, holding time, alkali amount with cooking, cooking vulcanization degrees this four factors, each factors change three conditions, the design becomes four factors, three conditions of orthogonal experiment. Then the results of the experiment test, main have potassium permanganate basically has value, the white degree and $\alpha$-the fiber content on average, DP, etc. According to the experimental results concluded the optimal process conditions. An optimum process condition in the process of prehydrolysis is at $150{ }^{\circ} \mathrm{C}$, time of $180 \mathrm{~min}$. The best cooking technology conditions of cooking is the highest temperature $155^{\circ} \mathrm{C}$, holding time $150 \mathrm{~min}$, alkaline $27 \%, 25 \%$ degree of vulcanization.

Keywords: Regenerated bamboo fiber, Hot water extraction, Prehydrolysis, Cooking orthogonal experiment.

\section{INTRODUCTION}

Bamboo fiber is a new type of regenerated cellulose fiber after soybean fiber in China. It's not only has the advantages of the natural fiber and synthetic fiber, but also has natural antibacterial properties, also have good ecological environmental protection property, it's a kind of renewable green fiber ${ }^{1}$. According to the difference of processing method, bamboo fiber can be divided into the natural bamboo fiber and regenerated bamboo fiber.

As bamboo pulp of spinning raw materials, it is derived from the instant fresh bamboo and rich resource. Land disposal, burning of the waste will not cause environmental pollution, it's belongs to environmental protection fiber and meet needs of green consumption. Bamboo fiber and viscose fiber have similar performance, bamboo fiber fabric have good hygroscopicity and breathability, good drapability and dyeing performance, with silk luster and feel and it have antibacterial, deodorization and UV protection function ${ }^{2}$. The natural characteristics of bamboo fiber make it monopolize seats in closefitting clothing textile fabric. As partial healthy nature of consumer consumption idea, bamboo fiber is a big underwear manufacturer. According to the difference of processing method, bamboo fiber can be divided into natural bamboo fiber and regenerated bamboo fiber.
Regenerated bamboo fiber with bamboo as raw material make the bamboo fiber which the combustion of cellulose content is in about $35 \%$ purified to $93 \%$ above through artificial catalytic, adopting hydrolysis sulfate process and multistage bleaching refining to make bamboo pulp satisfied the requirement of fiber production, made fiber waste-water processing again. After repeated process test to prove: fiber fineness and whiteness is close to ordinary viscose fiber, better strength, uniform and stable, toughness, high abrasion resistance and good spinning performance. The yarn and fabric made from fibers are detected by chemical fiber products testing center of chemical fiber industry association and national cotton dyeing and printing products quality supervision and testing center and the quality indicators is first grade. Regenerated bamboo fiber is not easy bleaching, dyeing, absorbent, strong penetration, rich silk feels, soft and smooth, it's ideal fabrics of high grade garments, underwear, sportswear, bedding, etc. ${ }^{3}$.

In order to further study regenerated bamboo fiber pulp, improving its yield (mainly $\alpha$-cellulose yield), the preparation technology of regenerated bamboo fiber pulp was studied systematically. This experiment is mainly to hydrolysis of bamboo fiber, sulfate cooking and the determination of $\alpha$ cellulose pulp, $\mathrm{k}$ value, whiteness, the average degree of polymerization, etc. after cooking. 


\section{EXPERIMENTAL}

2-Hydroxy toluene solution; aniline acetate solution; xylose $\left(\mathrm{C}_{6} \mathrm{H}_{10} \mathrm{O}_{5}\right)$; analytically pure $\mathrm{ABS}$; analytically pure $\mathrm{AQ}$; copper ethylenediamine solution.

Shaanxi University of Science and Technology, machinery factory ZQJ - B - type II pattern take copy; Nanjing jie YYG science and technology development co., LTD. 3-10-1. 25 digester type oil bath; The BrookField modernization type viscometer (high viscosity).

Raw material sources: Bamboo chip is about 20-40 mm long and 3 to $5 \mathrm{~mm}$ thick for future use. In this experiment, the original bamboo storage is relatively simple, on the floor basement seal preservation. Bamboo powder preparation, a small part of the raw materials have been dried, place grinder in the ground to a fine at the end of the sieve, interception by $0.38 \mathrm{~mm}$ mesh (40 eyes) and not through the $0.25 \mathrm{~mm}$ mesh (60 eyes) of fine at the end of the sealing bag used for analysis.

Experimental method: The preparation of regenerated bamboo fiber pulp use prehydrolytic sulfate process ${ }^{4}$. To date, a variety of pretreatment methods to hydrolyze and fractionate hemicellulose components have been investigated. These methods include steam explosion-based extraction, steam pretreatment with addition of catalyst, dilute acid pretreatment, hot water extraction, lime pretreatment, wet oxidation, ammonia fiber explosion and the use of solvents such as alcohols ${ }^{5-7}$.

Hot water extraction does not use chemicals such as acid, alkali considered as low cost and environmentally friendly. Without plant fiber raw material for reducing particle size of grinding processing, low energy consumption. Hydrolysis of hemicellulose hydrolysis rate and recovery rate is high, the product of neutral residue quantity less. So, it has an excellent prospect, it's currently one of the most promising hemicellulose pre extraction methods ${ }^{8}$.
Process flow as follows': First the raw materials composition analysis, then water temperature single factor and time factor are analyzed in the process of water prehydrolysis and the four factors of cooking: the highest cooking temperature, the holding time of the highest cooking temperature, degree of vulcanization, alkali charge, orthogonal experiment was carried out.

\section{RESULTS AND DISCUSSION}

Raw material composition analysis (Table-1): Respectively for determination of moisture and ash content of the raw materials, the determination of acid insoluble lignin content in the raw materials, the determination of pentosan, the determination of cellulose content in the raw material. Main reference for later experiment.

Water prehydrolysis single factor analysis: Hot water extraction hemicellulose process simple, reaction can be done in digester, extraction does not use chemicals such as acid, alkali, low cost, pollution-free, hemicellulose hydrolysis rate and recovery rate is high, extract is easy to separation and purification.

It can get high yield of hemicellulose transformation sugars after hot water extraction, hydrolysis products can be directly used to produce ethanol fermentation. In addition, hemicellulose and lignin has a reputation for LCC (lignincomplex carbohydrates) hang together, the dissolution of hemicellulose, can improve reactivity of lignin, can also improve penetration of liquids, thus improve cooking degree of delignification, reduce kappa number, shorten cooking time, reduce chemical consumption, also reduce black liquor pollution load and alkali recovery processing cost. Studies shown that under relatively mild conditions extracted part hemicellulose before cooking, this technology will have no negative influence on

\begin{tabular}{|c|c|c|c|c|c|c|}
\hline \multicolumn{7}{|c|}{$\begin{array}{c}\text { TABLE-1 } \\
\text { COMPOSITION ANALYSIS OF BAMBOO RAW MATERIAL }\end{array}$} \\
\hline \multirow{2}{*}{ Ash content (\%) } & \multirow{2}{*}{$\begin{array}{l}\text { Acid accumulator } \\
\text { insoluble lignin }(\%)\end{array}$} & \multicolumn{3}{|c|}{ Extraction (\%) } & \multirow{2}{*}{ Pentosan $(\%)$} & \multirow{2}{*}{ Cellulose (\%) } \\
\hline & & Hot-water & $1 \% \mathrm{NaOH}$ & Benzene-ethanol soluble & & \\
\hline 1.057 & 22.918 & 6.052 & 26.692 & 7.096 & 21.942 & 45.354 \\
\hline
\end{tabular}

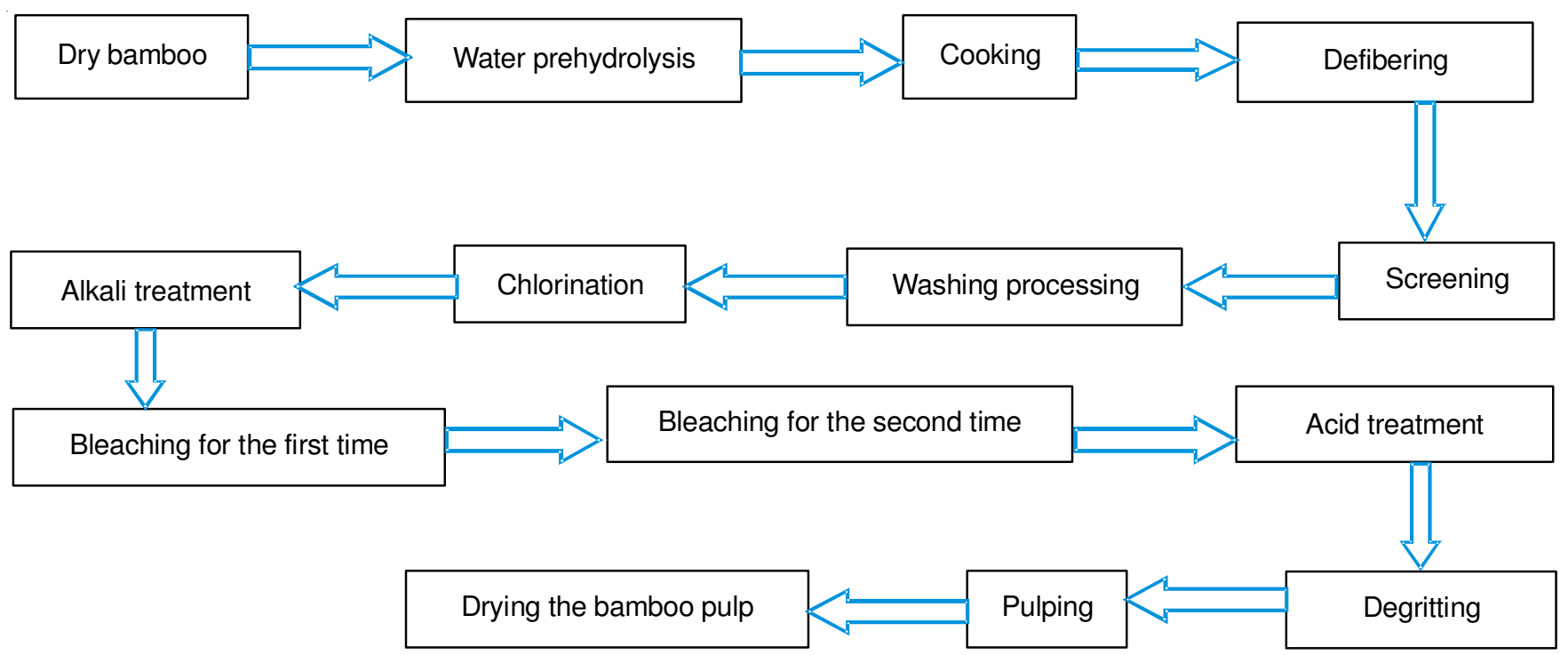


fiber quality and quantity ${ }^{11}$ and it's the developing direction of hemicellulose extraction process in the future.

Therefore, discusses conditions for hot water extraction hemicellulose, to determine the optimum temperature and time. First make two sets of single factor analysis of hot water extraction hemicellulose: single factor analysis of prehydrolysis temperature, single factor analysis of prehydrolysis time.

Prehydrolysis temperature single factor analysis: In experiments, liquor ratio of prehydrolysis is $1: 8$, the time 120 min. According to the operating requirement of YYG 3-10-1. 25 oil bath type cookers, setting pot quantity are $100 \mathrm{~g}$. According to the average moisture content of bamboo, calculate the raw material quality when the capacity of oven dry is $100 \mathrm{~g}$ and then calculate the volume of water added. Temperature: $70,90,110,130,150$ and $170{ }^{\circ} \mathrm{C}$.

The the factor content ${ }^{10}$ is shown in the Table- 2 after hydrolysis.

Experimental results analysis of prehydrolysis temperature single factor:

(I) The hydrolysis bamboo yield is falling as the temperature rising by the single factor analysis of hydrolysis temperature.

(II) It can be seen that bamboo blues content is falling as the temperature rising through the hydrolyzing bamboo blues content, but in $170{ }^{\circ} \mathrm{C}$ when the ash content is increasing a little. So in terms of the determination of ash content and $150{ }^{\circ} \mathrm{C}$ is the best process conditions.

(III) Cellulose content reached the highest in $150{ }^{\circ} \mathrm{C}$, so $150{ }^{\circ} \mathrm{C}$ is the best process conditions.

(IV) Pentosan content display n type change, first increase and then decrease. The most appropriate is $150{ }^{\circ} \mathrm{C}$, at this time in addition to pentosan content is higher than $170^{\circ} \mathrm{C}$, but pentosan content is lower than other temperature. $150{ }^{\circ} \mathrm{C}$ is the best process conditions, due to low cellulose content in $170{ }^{\circ} \mathrm{C}$.

(V) The lowest acid insoluble lignin content in $170{ }^{\circ} \mathrm{C}$ by observing the lignin measurement table after prehydrolysis, namely the highest removal rate of lignin.
Comprehensive considering other groups of factors, such as yield, cellulose content, hemicellulose content and so on. So $150{ }^{\circ} \mathrm{C}$ is the best process conditions in the prehydrolysis temperature single factor analysis.

Prehydrolysis time single factor analysis: In experiments, liquor ratio of prehydrolysis is $1: 8$, the prehydrolysis temperature is $150{ }^{\circ} \mathrm{C}$, prehydrolysis time, respectively is 90 , $120,150,180$ amd $210 \mathrm{~min}$.

The content of various factors ${ }^{10}$ is shown in Table-3 after determination.

The experimental results analysis of prehydrolysis time single factor analysis:

(I) It can be obtained yield is falling as the time rising by observation moisture content and yield after bamboo chip dried out. Between 180 and 210 min has small difference, so draw a conclusion that moisture content and yield have stabilised at around $180 \mathrm{~min}$.

(II) As the prehydrolysis time rising ash removal rate is rising by observed ash content after prehydrolysis, it reached the highest at $180 \mathrm{~min}$ and then began to decline. In combination with yield consideration can be obtained yield and ash removal rate are better process conditions when the prehydrolysis time is $180 \mathrm{~min}$.

(III) As the extension of the prehydrolysis time, cellulose content display $n$ type change, first increase and then decrease.

(IV) pentose content is the highest at 150 and $120 \mathrm{~min}$ is the lowest by observed pentose content determination after prehydrolysis.

(V) It can be seen the lowest acid insoluble lignin content is at $90 \mathrm{~min}$, namely the highest removal rate of lignin.

Comprehensive considering other groups of factors, such as yield, cellulose content, hemicellulose content and so on. So $180 \mathrm{~min}$ is the best process conditions in the prehydrolysis time single factor analysis.

Sulfate cooking: Cooking conditions, setting the cooking temperature, holding time, cooking alkali charge and cooking degree of vulcanization, each factor changed three conditions, designed four factors three levels of L9 $\left(3^{4}\right)$ orthogonal

\begin{tabular}{cccccc} 
& \multicolumn{5}{c}{ TABLE-2 } \\
RESULT OF PREHYDROLYSIS TEMPERATURE SINGLE FACTOR ANALYSIS \\
\hline $\begin{array}{c}\text { Prehydrolysis } \\
\text { temperature }(\%)\end{array}$ & Yield $(\%)$ & $\begin{array}{c}\text { Ash content } \\
(\%)\end{array}$ & $\begin{array}{c}\text { Cellulose } \\
\text { content }(\%)\end{array}$ & $\begin{array}{c}\text { Pentosan } \\
\text { content }(\%)\end{array}$ & $\begin{array}{c}\text { Acid accumulator insoluble } \\
\text { lignin content }(\%)\end{array}$ \\
\hline Raw material & 100.00 & 1.06 & 45.35 & 20.54 & 22.92 \\
70 & 98.78 & 0.64 & 49.23 & 21.61 & 21.48 \\
90 & 98.25 & 0.50 & 49.35 & 21.37 & 24.83 \\
110 & 97.37 & 0.41 & 49.79 & 21.52 & 2.56 \\
130 & 95.07 & 0.28 & 50.72 & 21.09 & 2.34 \\
150 & 90.35 & 0.14 & 50.79 & 20.45 & 19.36 \\
170 & 71.23 & 0.17 & 47.44 & 11.63 & \\
\hline
\end{tabular}

\begin{tabular}{|c|c|c|c|c|c|}
\hline \multicolumn{6}{|c|}{$\begin{array}{c}\text { TABLE-3 } \\
\text { RESULT OF PREHYDROLYSIS TIME SINGLE FACTOR ANALYSIS }\end{array}$} \\
\hline $\begin{array}{l}\text { Prehydrolysis } \\
\text { time (min) }\end{array}$ & $\begin{array}{l}\text { Yield } \\
(\%)\end{array}$ & $\begin{array}{c}\text { Ash } \\
\text { content }(\%)\end{array}$ & $\begin{array}{c}\text { Cellulose } \\
\text { content }(\%)\end{array}$ & $\begin{array}{c}\text { Pentosan } \\
\text { content }(\%)\end{array}$ & $\begin{array}{l}\text { Acid accumulator insoluble } \\
\text { lignin content }(\%)\end{array}$ \\
\hline Raw material & 100.00 & 1.06 & 45.35 & 20.54 & 22.92 \\
\hline 90 & 93.44 & 0.17 & 46.81 & 22.06 & 20.55 \\
\hline 120 & 90.35 & 0.12 & 50.79 & 20.45 & 28.80 \\
\hline 150 & 90.01 & 0.12 & 49.04 & 22.27 & 22.84 \\
\hline 180 & 89.87 & 0.20 & 45.49 & 21.15 & 23.77 \\
\hline 210 & 88.22 & 0.14 & 45.20 & 20.47 & 23.82 \\
\hline
\end{tabular}


experiment $^{12}$ (Table-4). Then test the experimental results ${ }^{10}$. Main yield, $\mathrm{k}$ value, whiteness, $\alpha$-cellulose content, average polymerization degree.

\begin{tabular}{ccccc}
\multicolumn{5}{c}{ TABLE-4 } \\
LIST OF ORTHOGONAL EXPERIMENT \\
\hline $\begin{array}{c}\text { Serial } \\
\text { No. }\end{array}$ & $\begin{array}{c}\text { Cooking } \\
\text { temperature } \\
\left({ }^{\circ} \text { C) }\right.\end{array}$ & $\begin{array}{c}\text { Degree of } \\
\text { vulcanization } \\
(\%)\end{array}$ & $\begin{array}{c}\text { Holding } \\
\text { time }(\text { min })\end{array}$ & $\begin{array}{c}\text { Alkali } \\
\text { charge }(\%)\end{array}$ \\
\hline 1 & 155 & 20 & 120 & 22 \\
2 & 155 & 25 & 150 & 27 \\
3 & 155 & 30 & 180 & 33 \\
4 & 165 & 20 & 150 & 33 \\
5 & 165 & 25 & 180 & 22 \\
6 & 165 & 30 & 120 & 27 \\
7 & 175 & 20 & 180 & 27 \\
8 & 175 & 25 & 120 & 33 \\
9 & 175 & 30 & 150 & 22 \\
\hline
\end{tabular}

The dosage of cooking reagent: ABS: $1.0 \%$, AQ: $0.1 \%$.

The test results of the pulp performance are shown in Table-5 after cooking.

Four elements range analysis of cooking experiment: The results of analysis can see from the Figs 1-5.

From (Fig. 1) can be obtained groups of range respectively is A 7.81, B 2.31, C 0.73, D 1.62. So the result of factor analysis and optimization combination is A-B-D-C, $\mathrm{A}_{1} \mathrm{~B}_{1} \mathrm{C}_{3} \mathrm{D}_{2}$.

From (Fig. 2) the obtained groups of range respectively is A 201.33, B 30.34, C 160.67, D 95.66. So the result of factor analysis and optimization combination is A-C-D-B, $\mathrm{A}_{1} \mathrm{~B}_{3} \mathrm{C}_{2} \mathrm{D}_{3}$.

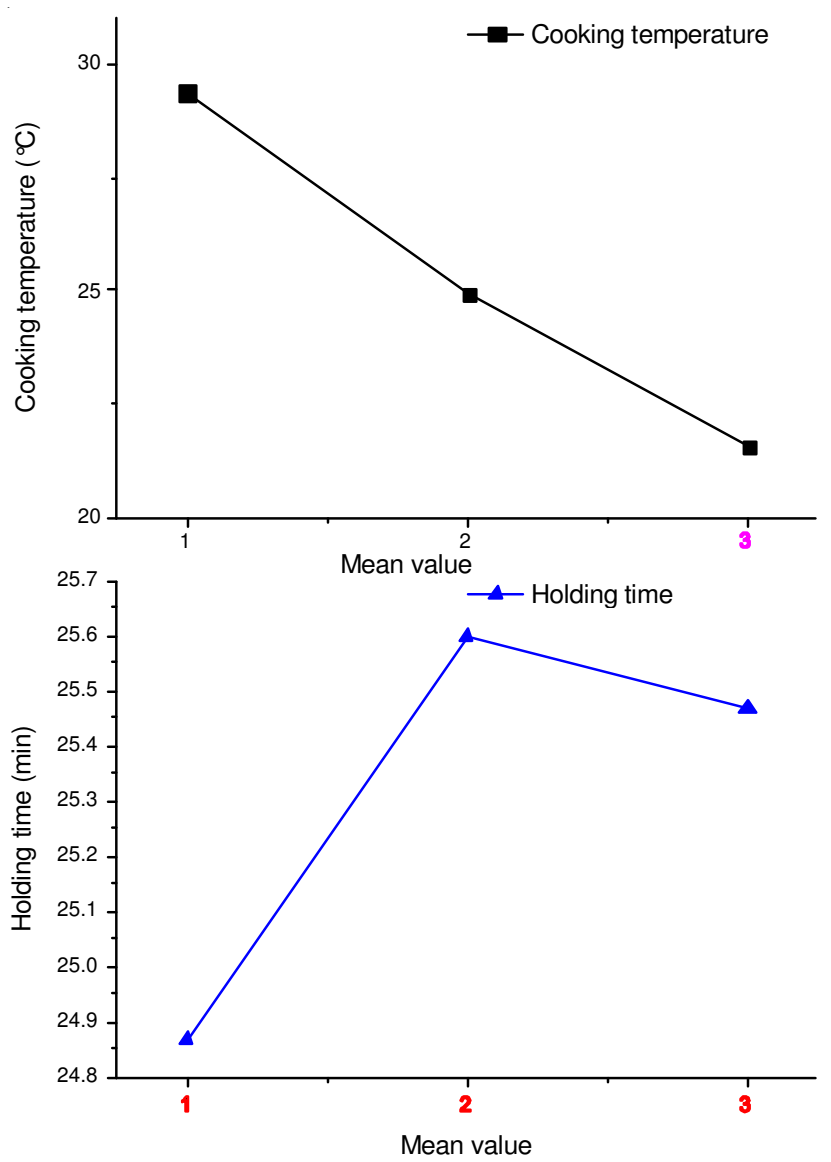

\begin{tabular}{cccccc}
\multicolumn{5}{c}{ TABLE-5 } \\
\hline $\begin{array}{c}\text { Serial } \\
\text { No. }\end{array}$ & $\begin{array}{c}\text { Yield } \\
(\%)\end{array}$ & DP & $\begin{array}{c}\text { ISO } \\
\text { brightness } \\
(\%)\end{array}$ & $\begin{array}{c}\text { K } \\
\text { value }\end{array}$ & $\begin{array}{c}\alpha \text {-Cellulose } \\
\text { yield (\%) }\end{array}$ \\
\hline 1 & 30.17 & 1306 & 27.1 & 11.2 & 95.04 \\
2 & 29.48 & 1113 & 32.3 & 11.4 & 95.70 \\
3 & 28.55 & 1036 & 34.5 & 10.8 & 94.19 \\
4 & 26.34 & 1251 & 28.9 & 10.9 & 92.69 \\
5 & 26.51 & 1347 & 32.0 & 9.1 & 94.15 \\
6 & 21.98 & 1461 & 39.4 & 12.3 & 94.58 \\
7 & 21.34 & 1165 & 18.3 & 13.5 & 94.36 \\
8 & 22.45 & 1213 & 34.2 & 12.5 & 94.43 \\
9 & 20.98 & 1134 & 38.7 & 11.9 & 94.60 \\
\hline
\end{tabular}

\begin{tabular}{ccccc}
\multicolumn{5}{c}{ TABLE-6 } \\
COMBINATION OF FACTORS TABLE \\
\hline \multirow{3}{*}{ Factor } & $\mathrm{A}$ & $\mathrm{B}$ & $\mathrm{C}$ & $\mathrm{D}$ \\
\cline { 2 - 5 } & $\begin{array}{c}\text { Cooking } \\
\text { temperature } \\
(\%)\end{array}$ & $\begin{array}{c}\text { Degree of } \\
\text { vulcanization } \\
(\%)\end{array}$ & $\begin{array}{c}\text { Holding } \\
\text { time (min) }\end{array}$ & $\begin{array}{c}\text { Alkali } \\
\text { charge (\%) }\end{array}$ \\
\hline 1 & 155 & 20 & 120 & 22 \\
2 & 165 & 25 & 150 & 27 \\
3 & 175 & 30 & 180 & 33 \\
\hline
\end{tabular}

From (Fig. 3) the obtained groups of range respectively is A 1.2, B 12.8, C 5.3, D 2.6. So the result of factor analysis and optimization combination is B-C-D-A, $\mathrm{A}_{1} \mathrm{~B}_{3} \mathrm{C}_{1} \mathrm{D}_{1}$.

From (Fig. 4) the obtained groups of range respectively is A 1.86, B 0.87, C 0.87, D 1.67. So the result of factor analysis and optimization combination is $\mathrm{B}-\mathrm{C}-\mathrm{D}-\mathrm{A}, \mathrm{A}_{2} \mathrm{~B}_{2} \mathrm{C}_{3} \mathrm{D}_{1}$.
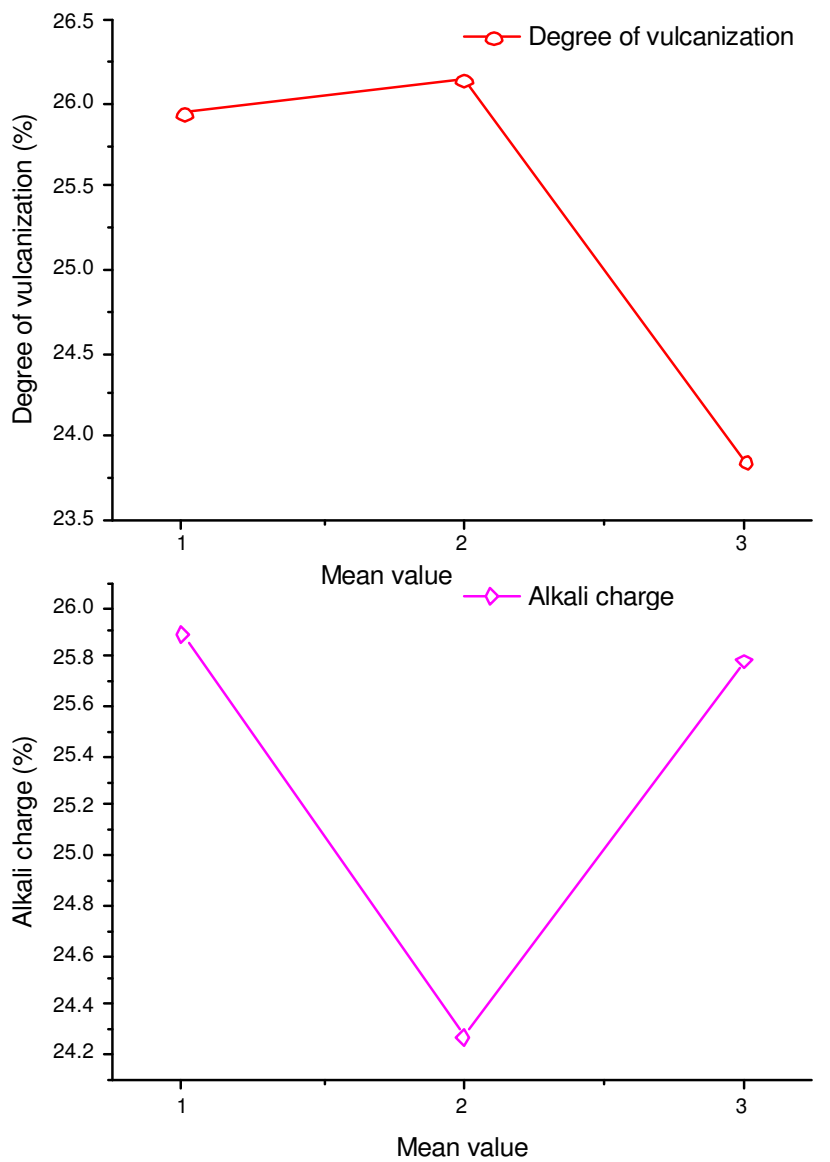

Fig. 1. Influence factors analysis of the yield 
From (Fig. 5) the obtained groups of range respectively is A 1.17, B 0.73, C 0.46, D 1.11. So the result of factor analysis and optimization combination is A-D-B-C, $\mathrm{A}_{1} \mathrm{~B}_{2} \mathrm{C}_{1} \mathrm{D}_{1}$.

Orthogonal experiment results analysis: Comprehensive considered after cooking pulp yield, content of $\alpha$-cellulose, whiteness, $\mathrm{k}$ value, average degree of polymerization, etc., it is to determine the optimal process conditions.
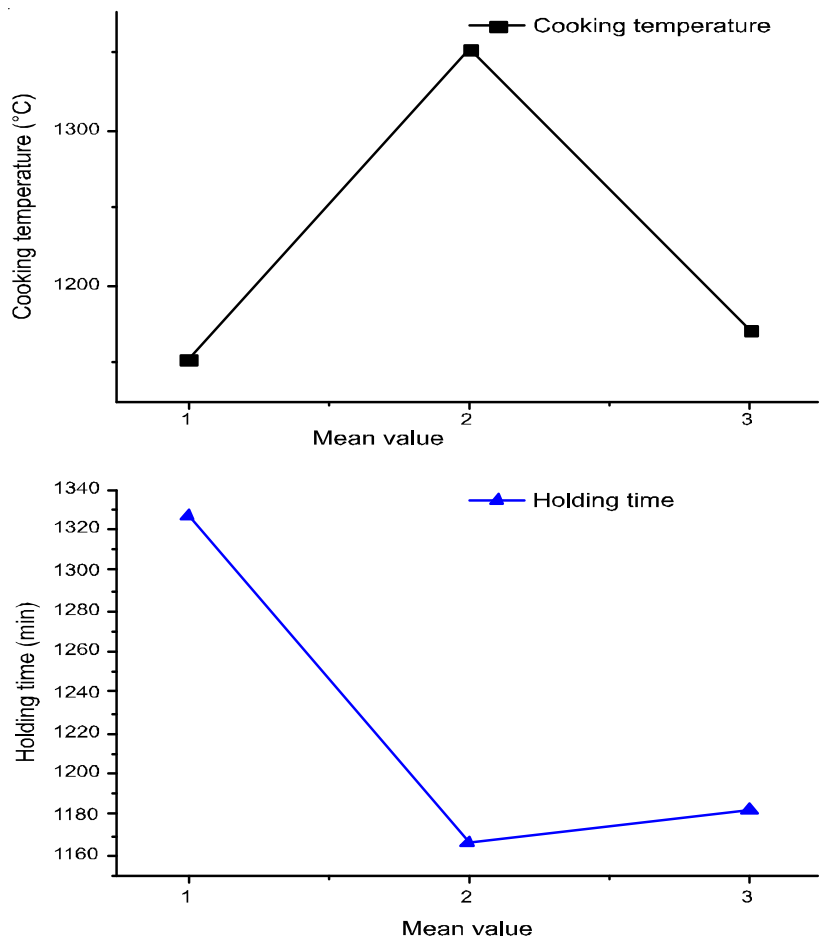

Fig. 2. Influence factors analysis of DP
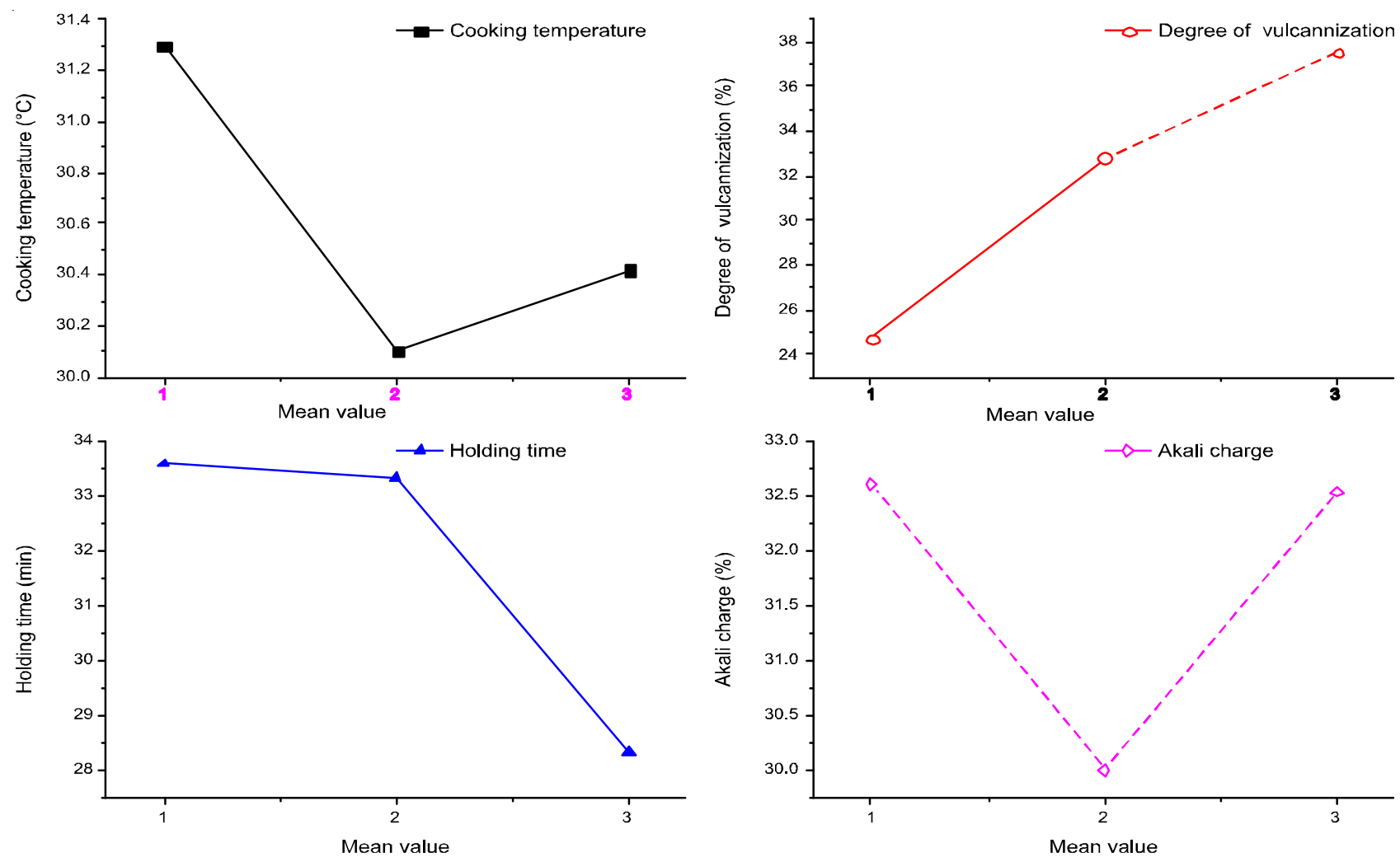

Fig. 3. Influence factors analysis of whiteness 

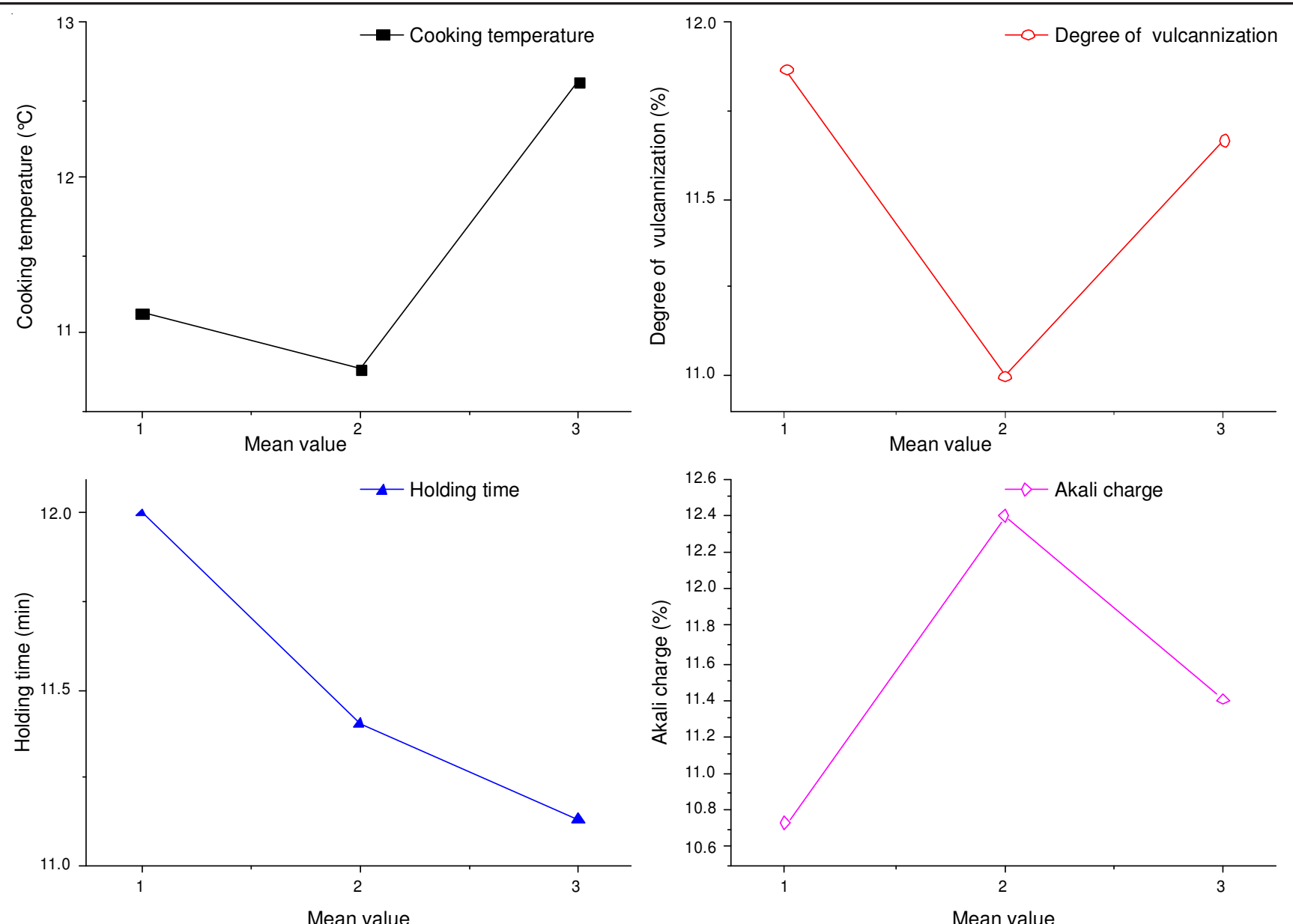

Fig. 4. Influence factors analysis of $\mathrm{k}$ value
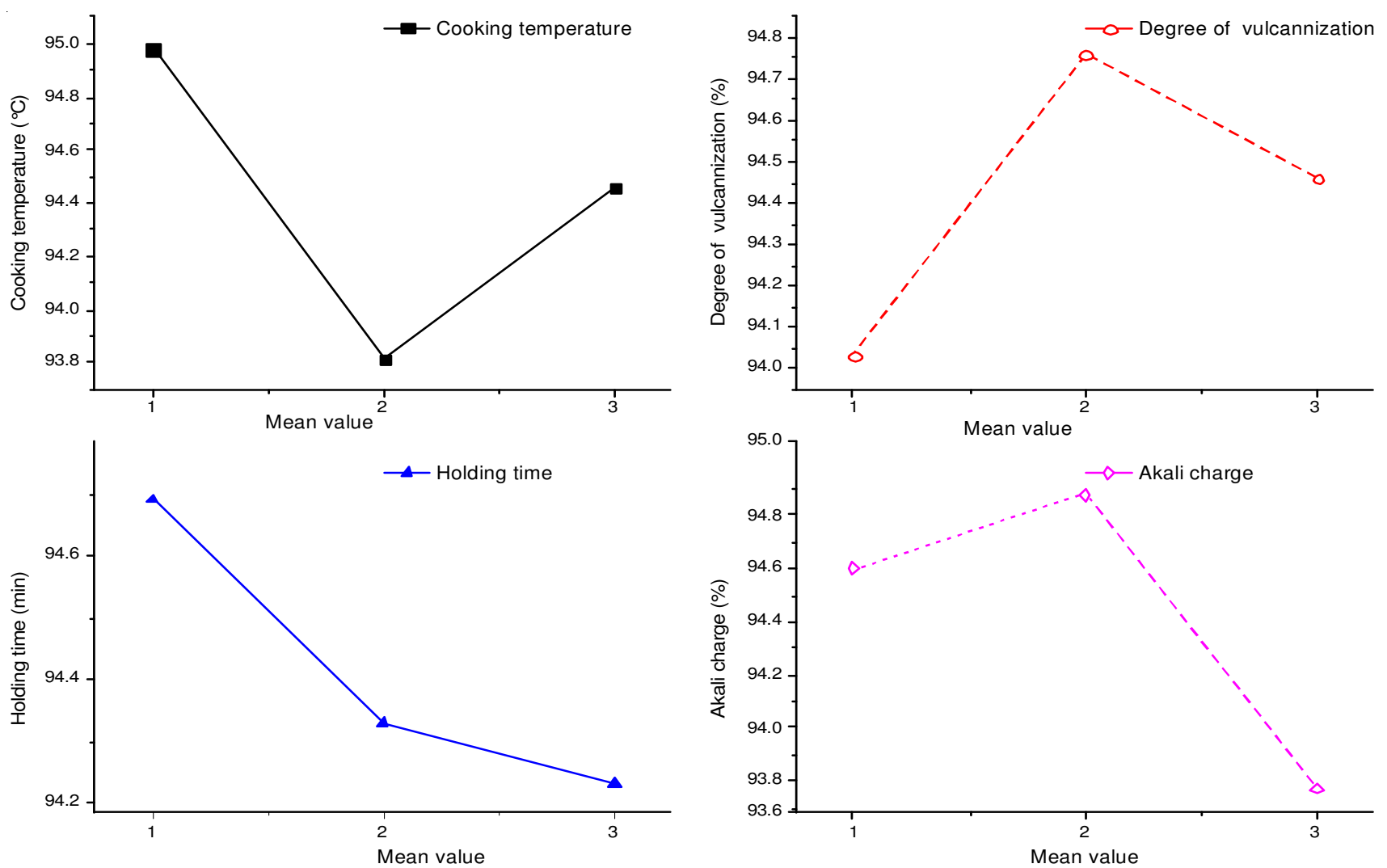

Fig. 5. Influence factor analysis of $\alpha$-cellulose 
Again from the holding time of the highest cooking temperature to discuss, as the extension of holding time, yield, $\mathrm{k}$ value, the content of $\alpha$-cellulose changed little; But the average degree of polymerization increased from 1166 to 1327 , it is minimum at $150 \mathrm{~min}$; Paper whiteness changes from $28.3 \%$ to $33.6 \%$, considering the influence of the liquid alkali residue on the subsequent bleaching, $150 \mathrm{~min}$ is appropriate. So, holding time is at $150 \mathrm{~min}$, as the optimal process conditions.

Consider alkali charge, with the increase of alkali charge, yield almost have no big change, whiteness changed little; But DP is from 1262 to 1246 , finally to $1166,22 \%$ and $27 \%$ with alkaline charge; $\mathrm{k}$ value increased from 10.7 to 12.4 , with $27 \%$ alkali charge is best. $\alpha$-Cellulose content is between $93.77 \%$ and $94.88 \%$, with $27 \%$ alkali charge is best. Comprehensive consideration, $27 \%$ alkali charge is the best technological conditions.

To compare from the aspects of cooking degree of vulcanization, with the increase of it, $\alpha$-cellulose changed little; DP and $\mathrm{k}$ value suffer very little. But yield changes from 23.84 to $26.15 \%$ and $25 \%$ of the degree of vulcanization is better. The most significant change is whiteness between $24.8 \%$ and $37.5 \%$, the best degree of vulcanization is $25 \%$. Choosing cooking degree of vulcanization is $25 \%$, as the optimal process conditions.

Optimum cooking conditions: The highest temperature $155^{\circ} \mathrm{C}$, the holding time of highest cooking temperature 150 min and cooking with $27 \%$ alkaline, cooking degree of vulcanization was $25 \%$.

\section{Conclusion}

The study discusses the optimal process conditions of the regenerated cellulose fiber pulp preparation technology based on bamboo raw material. Main task is to pre hydrolyzing boiled single factor analysis and orthogonal test. The optimum process conditions in the process of the prehydrolysis: the prehydro- lysis temperature is $150^{\circ} \mathrm{C}$, time $180 \mathrm{~min}$. Best cooking process conditions: liquid ratio $1: 4$, pan quantity $100 \mathrm{~g}$, the highest cooking temperature $155^{\circ} \mathrm{C}$, the holding time $150 \mathrm{~min}$ and cooking with $27 \%$ alkali charge, $25 \%$ cooking degree of vulcanization. Cooking ABS $1.0 \%$, cooking AQ $0.1 \%$, heating mode of cooking: initial temperature $90{ }^{\circ} \mathrm{C} \rightarrow$ heat up to $100{ }^{\circ} \mathrm{C} \rightarrow 120^{\circ} \mathrm{C} \rightarrow 155^{\circ} \mathrm{C}$ keep $150 \mathrm{~min}$. The bamboo pulp fiber performance obtained in the optimum process conditions is as follows: $29.48 \%$ yield, $32.3 \%$ ISO brightness, $\mathrm{k}$ value $11.4,1113 \mathrm{DP}, \alpha$-cellulose content is $95.70 \%$.

\section{ACKNOWLEDGEMENTS}

The authors appreciated the Innovation Project of Guangxi Graduate Education (YCBZ2012003), the Scientific Research Foundation of Guangxi University (Grant No. XJZ13066) and Guangxi Natural Fund (2012GXNSFAA053023) \& (2013GXNSFFA019005).

\section{REFERENCES}

1. B. Zhao, Modern Sci. Technol. Silk, 1, 18 (2011).

2. Y. Zhang et al., Textile and Quality Standard, 4, 21 (2003).

3. J.F. Zhu, Knitting Industry, 6, 23 (2003).

4. A.H. Zhong and L.Z. Wu, Wool Spinning Sci. Technol., 8, 57 (2004).

5. W.R. Kenealy, C.J. Houtman, J. Laplaza, T.W. Jeffries and E.G. Horn, ACS Symp. Ser, 954, 392 (2007).

6. H. Jørgensen, J.B. Kristensen and C. Felby, Biofuels Bioprod. Bioref., 1, 119 (2007).

7. H.-J. Huang, S. Ramaswamy, U.W. Tschirner and B.V. Ramarao, Sep. Purif. Technol., 62, 1 (2008).

8. S.F. Zhang and H. Yang, Paper and Paper Making, 30, 30 (2011).

9. J. Xu and Y.T. Jiang, J. Bamboo Res., 24, 39 (2005).

10. S.L. Shi, Analysis and Detection of Pulping and Papermaking, China Light Industry Press, BeiJing, (2010).

11. W.W. Al-Dajini and U.W. Tschimer, Holzforschung, 64, 411 (2010).

12. Z. Hung and H. Yingbo, Shanghai Textile Sci. Technol., 32, 9 (2004). 